\title{
BMJ Open Quality of life and coping strategies among immigrant women living with pain in Denmark: a qualitative study
}

\author{
Camilla Michaëlis, ${ }^{1}$ Maria Kristiansen, ${ }^{2,3}$ Marie Norredam $^{1,3}$
}

To cite: Michaëlis C, Kristiansen M, Norredam M. Quality of life and coping strategies among immigrant women living with pain in Denmark: a qualitative study. BMJ Open 2015;5:e008075. doi:10.1136/bmjopen-2015008075

- Prepublication history for this paper is available online. To view these files please visit the journal online (http://dx.doi.org/10.1136/ bmjopen-2015-008075).

Received 4 March 2015 Revised 10 June 2015 Accepted 22 June 2015

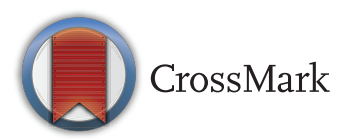

\footnotetext{
${ }^{1}$ Section of Immigrant Medicine, Department of Infectious Diseases, Copenhagen University Hospital, Hvidovre, Denmark ${ }^{2}$ Department of Public Health, Center for Healthy Aging, University of Copenhagen, Copenhagen, Denmark ${ }^{3}$ Department of Public Health, Danish Research Center for Migration, Ethnicity and Health, University of Copenhagen, Copenhagen, Denmark
}

\section{Correspondence to} Camilla Michaëlis; cgn966@alumni.ku.dk

\section{ABSTRACT}

Objective: To examine quality of life and coping strategies among immigrant women living with chronic pain.

Design: Qualitative content analysis based on in-depth semistructured interviews.

Setting: A clinic specifically targeting immigrants at a larger university hospital in Copenhagen, Denmark.

Participants: Non-western female immigrant patients suffering from chronic pain $(n=13)$.

Main outcome measures: Experiences of the impact of chronic pain on quality of life.

Results: Chronic pain was perceived to have an extensive, adverse effect on all aspects of quality of life, including physical health, mental well-being and social relations. This included the ability to maintain activities of daily living and the ability to work. Chronic pain was further experienced as a cause of emotional distress, depression and altered personalities, which all had great consequences on women's social

interactions, causing change and loss of social relations. A variety of coping strategies were used to cope with the pain, manage its consequences, and restore a level of health that would enable women to function and fulfil social roles. Many participants coped with the pain by altering everyday life, keeping daily activities to a minimum and taking pain-killing drugs, offering temporary relief. Seeking healthcare was another coping strategy used as an active means to assert agency and as a temporary distraction from pain. However, accessing healthcare also involved a risk of disagreement and disappointments.

Conclusions: Chronic pain had a severe negative impact on quality of life and necessitated alterations in everyday life and active health-seeking strategies. Implications for practice imply a need for a more holistic approach to immigrant women with chronic pain, including a family-centred approach. Further research is needed to explore similarities or differences in and between populations with diverse ethnic, socioeconomic and psychosocial backgrounds, and to assess how ethnicity and culture might influence the experiences of chronic pain.

\section{INTRODUCTION}

Chronic pain is defined as pain that has lasted longer than 3 months $^{1}$ and it

\section{Strengths and limitations of this study}

- The in-depth, qualitative approach enabled us to identify the experience of the influence of living with chronic pain on quality of life among immigrant women.

- The study elucidates patient perspectives among a patient group with complex needs and thus points to important ways of improving quality of care for them.

- The quality of data collation is likely impeded by language barriers.

- The lack of longitudinal and multiperspective data is a further limitation of this study.

constitutes a common health problem in many European countries, including Denmark. $^{2}$ The prevalence of moderate to severe pain is estimated to be $16-19 \%$ among the adult Danish population. ${ }^{2-5}$

Living with chronic pain is challenging, as it seriously affects quality of life and interferes with normal physical, social and physiological functions. Therefore, patients living with chronic pain are more likely to suffer from sleeplessness, depression, emotional distress, low self-esteem and anxiety. ${ }^{5-9}$ The pain experience interferes with the ability to work, undertake household chores, exercise, attend social activities and maintain an independent lifestyle, ${ }^{5} 7$ and therefore also has consequences for relationships with family and friends, etc. ${ }^{6}$ Chronic pain is considered a public health problem with evident consequences for the individual patient as well as for family members, healthcare providers and society, overall. ${ }^{2}$

Chronic pain is reported to be more common among women, ${ }^{2}{ }^{9}{ }^{10}$ groups with lower educational levels and lower income, groups living in compromised housing areas, individuals with lack of personal support ${ }^{9}$ and among immigrants. The literature shows that the prevalence of chronic pain is higher among immigrants in Europe than among 
the native European population. ${ }^{3} 81011$ A recent Danish study found that individuals with a non-western background have a significantly higher risk of reporting chronic pain than those with a Danish background. ${ }^{3}$ In addition, quantitative research has found that widespread pain is more prevalent among individuals with a non-western background, who also reported higher levels of pain intensity and increased disability associated with chronic pain, consistent with previous international findings, ${ }^{3}{ }^{11}$ especially among female immigrants. ${ }^{3}{ }^{12}$

Chronic pain is a result of biological, physiological and social factors, ${ }^{9}$ and the interplay between the underlying causes is complex, affected by characteristics such as age, gender, culture and socioeconomic resources, ${ }^{13} 14$ as well as the migration processes, which are known to include a potential health risk affecting both physical and mental health. ${ }^{13}$ This makes immigrants, especially women, a particularly vulnerable group. However, there is great diversity both within and between ethnic groups, and the varying exposures to these and other factors can lead to differences. ${ }^{15}$ In addition, pain perception takes place in a context of an individual's environment, including the physical, social and emotional context, ${ }^{16}$ and may therefore be perceived and coped with differently by different ethnic groups. ${ }^{8} 111718$ The resources of the individual, including characteristics such as gender, cultural background and socioeconomic factors, as well as the responses to ethnic diversity by healthcare, further affect coping strategies. ${ }^{8} 15$

Affiliation to an ethnic group or being an immigrant may not necessarily be responsible for differences in the perception and experience of pain, as these variations are affected and sometimes better explained by socioeconomic status and level of education. ${ }^{15}$ However, immigrants make up a vulnerable group as they are affected by a series of factors, also making the access to healthcare services in the destination country difficult. Immigrants often struggle with language difficulties and health illiteracy, ${ }^{19} 20$ and, additionally, healthcare professionals may experience challenges due to language and cultural differences in encounters, leading to misunderstandings and frustrations from the perspectives of the patients as well as the healthcare providers, and resulting in poorer treatment and clinical mistakes at worst. ${ }^{13} 21$

A number of quantitative studies have illustrated that chronic pain is a major health problem with significant adverse effects on many aspects of a patients' life and, thus, reduced quality of life. ${ }^{2-5} 7$ Relatively fewer studies have explored the experiences of living with chronic pain and how it affects quality of live including physical, daily and social activities, and mental well-being and knowledge is scarce about lived experiences of and coping with chronic pain among immigrant patients. By this qualitative perspective, we aim to provide in-depth, contextualised insight into the lived experiences of chronic pain and coping strategies utilised to manage a life with chronic pain among immigrant patients. Elucidating patient perceptions is thus an important step in identifying unmet needs and avenues for intervention to support this patient group. The overall aim of our study was, therefore, to examine the experiences of immigrant women living and coping with chronic pain. The knowledge is important to identify the impact of pain on the patient, and the unmet need for health and social care services.

The following research questions were investigated:

1. How is chronic pain perceived to be affecting the quality of life among immigrant women?

2. Which coping strategies do these women employ in order to manage chronic pain?

\section{METHODS}

\section{Setting}

The study was conducted at the Section of Immigrant Medicine (SIM), Department of Infectious Diseases, at a larger hospital in the vicinity of Copenhagen, Denmark. SIM is a medical outpatient service for immigrants, specifically dedicated to vulnerable immigrants of different ethnic, primarily non-western, backgrounds, who are experiencing complex health problems. Patients at SIM constitute a rather diverse group with complex psychosocial and medical challenges. However, the patients shares a number of characteristics, in particular, related to socioeconomic background, migrant status and experiences with long-term treatment trajectories. Many of these patients are referred to physiotherapy and occupational therapy because of experiences with chronic pain, muscle tension and physical inactivity. Consequently, this was a relevant setting for our study as we wished to explore the experience of living with chronic pain among immigrant women, in particular how the pain was perceived to affect quality of life and the coping strategies employed due to pain.

\section{Inclusion criteria and data collection}

Purposeful sampling was used in selecting participants. Inclusion criteria for participation in the study were as follows: (1) all patients at SIM referred to physiotherapy and occupational therapy and rehabilitation because of chronic pain, muscle tension, physical inactivity and physical disabilities; (2) country of birth (including only women born in non-western countries) and (3) an age of 18 and older. Participants differed with regard to type of health problems and length of treatment trajectory.

The first author was affiliated with the clinic during a 6-month period, and a combination of recruitment, participant observation and semistructured interviews was carried out. Participant observation took place over a period of 2 months during the physiotherapy sessions. Recruitment of patients took place during observations, when patients were introduced to the researcher and established a more trusting relationship with her. One woman refused to participate in the study due to lack of time, and another woman did not complete the interview, as it was not a therapeutic or healthcare-related examination. 


\section{Box 1 Topics of the semistructured interview guide}

Background information: country of birth, migration experience and time spent in Denmark, social relations in Denmark, labour market attachment.

- The experience of pain: duration, perceptions of the pain and its causes, coping strategies.

- Everyday life: influence of pain on activities of daily living, quality of life, and social relations, roles and responsibilities within families, social and practical support, and identity.

- Treatment and expectations for the future: expectations for the future with regard to the management of chronic pain and treatment options.

Participant observation further functioned as a source of insight into pain experiences, coping strategies and encounters between patients and healthcare professionals. This contextual information fed into the interview guide, and was included during interviews and analysis. A total of 13 in-depth interviews were carried out between October and November 2014 by the first author. Interviews were semistructured and based on an interview guide (see box 1 for topics discussed during interviews). To contextualise the experiences of chronic pain, questions regarding general health, socioeconomic status and social relations were asked. The interview guide was pilot tested and minor adjustments were made to lower the risk of misunderstandings arising out of language differences. One interview was conducted with each interviewee at the clinic. Interviews lasted between 17 and $90 \mathrm{~min}$. All patients were offered professional interpreters to ensure inclusion of patients who spoke little or no Danish. A total of four patients preferred an interpreter, and, in these cases, an online video interpreter was employed. The remaining interviews were conducted in Danish since those patients were sufficiently fluent in Danish to ensure a meaningful conversation. During interviews, clarifying questions were used to ensure that the questions were adequately understood by the patients. Only the patient and the researcher were present during the interview. Immediately after the sessions, notes related to immediate impressions were taken and used in the subsequent analysis as contextual information. Initial analysis was conducted after each interview, and data collection was continued until a saturation point was achieved.

\section{Data analysis}

Data were analysed through content analysis focusing on experiences and perceptions related to living with chronic pain. Interviews were fully transcribed and transcripts and reflection notes were both used. Data were analysed according to Malterud's guidelines for qualitative analysis and systematic text condensation. ${ }^{22}$ First, the transcribed interviews were read several times to obtain an impression of the text as a whole. Second, meaningful units were identified and categorised in all interviews. Third, data were reduced to a decontextualised selection of meaningful units categorised as thematic codes across the interviews. Finally, descriptions and concepts were summarised into main findings. These were discussed within the research group and with researchers from cross-disciplinary backgrounds. In the presented results, the grammatical structures of the quotations were slightly altered to make them more readable. To ensure that no meanings were lost in the process, every transcribed quotation was analysed and discussed in-depth by the three authors.

\section{Ethics}

Patients were introduced to the study by their physiotherapist. Subsequently, the women were approached in person by the researcher who presented herself, explained the aim of the study, ensured their willingness to participate and provided an information letter in Danish detailing the aims of the study, and research ethics, including anonymity, storage of data and the right to discontinue participation at any time. Some of the women received further oral explanation from their physiotherapist. A professional interpreter in their native tongue was offered to all interviewees. Before the interviews, the women were informed that the interviews would be taped and it was ensured that participants understood their rights and the purpose of the study. All participants signed a declaration of informed consent in an appropriate language. They were also able to contact the interviewer after the interview. It was further ethically approved by the ethics board at the hospital where data collection took place. The study was conducted in accordance with ethical principles for medical research proclaimed by the Helsinki declaration.

\section{RESULTS}

All participants were non-western immigrant women who had migrated to Denmark from Turkey, Iraq, Afghanistan, Somalia, Pakistan, Jordan or Morocco. They represented some of the major immigrant groups in Denmark ${ }^{23}$ and had arrived primarily as refugees or through family reunification. The women were between the ages of 33 and 63 years, and had lived in Denmark between 11 and 40 years. Eight women were married, five divorced and all but one had children. Most of the women had previously had regular work, but all were excluded from the labour market due to pain. The women had suffered from chronic pain between 4 and 23 years. While for some there was a diagnosed underlying disease causing the pain, this was not the case for most of them. Chronic pain, in this study, refers to the experiences of living with pain for more than 3 months, regardless of diagnosis. An overview of the informants is presented in table 1.

In the following, we will present the results divided into two main themes: experiences of chronic pain and coping with chronic pain. Categories extracted from the 
Table 1 Characteristics of interviewees $(n=13)$

\begin{tabular}{|c|c|c|c|c|c|c|}
\hline Participants & Age & Family situation & $\begin{array}{l}\text { Native } \\
\text { country }\end{array}$ & $\begin{array}{l}\text { Years in } \\
\text { Denmark }\end{array}$ & Pain location & $\begin{array}{l}\text { Lengths of pain } \\
\text { experiences, in } \\
\text { years }\end{array}$ \\
\hline P1 & $30-40$ & Married, 2 children & Pakistan & $25-29$ & Generalised pain & 11 \\
\hline $\mathrm{P} 2$ & $40-50$ & Divorced, 3 children & Iraq & $10-14$ & Neck, back, head & 11 \\
\hline P3 & $50-60$ & Married, 5 children & Jordan & $25-29$ & $\begin{array}{l}\text { Shoulders, arms, } \\
\text { generalised pain }\end{array}$ & 4 \\
\hline P4 & $50-60$ & Married, 6 children & Iraq & $25-29$ & Generalised pain & 4 \\
\hline P5 & $40-50$ & Married, 3 children & Turkey & $25-29$ & Shoulders, arms, feet & 9 \\
\hline P6 & $30-40$ & Divorced, 2 children & Afghanistan & $20-24$ & $\begin{array}{l}\text { Head, neck, shoulders, } \\
\text { arms }\end{array}$ & 4 \\
\hline P7 & $50-60$ & Divorced, 3 children & Morocco & $40-44$ & Generalised pain & 10 \\
\hline P8 & $30-40$ & Married, 5 children & Afghanistan & $15-19$ & $\begin{array}{l}\text { Shoulders, back, neck, } \\
\text { head, legs }\end{array}$ & 19 \\
\hline P9 & $30-40$ & Married, 3 children & Turkey & $15-19$ & Back, legs, kidney & 3 \\
\hline P10 & $60-70$ & Married, 5 children & Turkey & $30-34$ & Back, legs, arms & 14 \\
\hline P11 & $50-60$ & Married, 4 children & Iraq & $20-24$ & Knees, neck, back & 15 \\
\hline P12 & $40-50$ & Divorced, 3 children & Turkey & $30-34$ & Back, feet, head & 23 \\
\hline $\mathrm{P} 13$ & $50-60$ & Divorced, 0 children & Somalia & $15-19$ & Shoulders, arms, legs & 5 \\
\hline
\end{tabular}

experiences of chronic pain included altered mental well-being and strained social relations. Within the theme of coping with chronic pain, altering everyday life and seeking healthcare is presented.

\section{Experiences of chronic pain}

Living with chronic pain affected the women's quality of life in several ways (figure 1). In the following, the consequences for their ability to maintain activities of daily living, their mental well-being and interactions with their social relations will be described.

\section{The negative impact on activities of daily living}

The experience of chronic pain had extensive consequences for women's lives, and their ability to continue their usual activities of daily living was limited by the physical impact of the pain. Some women described impaired everyday activities related to putting on clothes, taking a shower, lifting shopping bags, going for a walk, taking the children to school, doing paperwork or sleeping, as a challenge. The women described how difficulties in sleeping, fatigue, limited energy and an increased need for rest, kept them from fulfilling their responsibilities and duties, forcing them to prioritise tasks and keeping everyday life to a minimum. Interviewees all experienced great difficulties in managing household chores such as cooking, cleaning, hoovering and shopping; however, only one received home help. A woman said:

House cleaning I cannot do and my house is dirty, but I have to do without a lot of things because I cannot carry it off. I need help from others [...] it is hell when I have to cook. I have to lie down and adjust the cooking to my pace and cook the easiest way $[\ldots]$. When I have to wash clothing, that day I do not cook, I simply cannot. (Pt 1)
The ability to undertake paid work was another area affected by the pain. Reduced physical capabilities required 10 of the women to retire from work, as the working conditions became too onerous. The exclusion from the labour market further impacted on the women's finances, forcing them into a poorer economic situation. Lack of money hindered their possibilities for seeking treatment and technical aids and, therefore, also opportunities for improvements. Some of the women expressed a need for appliances such as a dishwasher or a washing machine to relieve the pain and ease everyday life, but did not have the finances to acquire these. Others mentioned being unable to attend regular treatment without transportation grants from the hospital. Furthermore, poor financial resources made it difficult to prioritise health.

\section{Altered mental well-being}

In addition, the experiences of living with chronic pain were perceived to be related to emotional distress including sadness, depression and a sense of isolation. Feelings of anger, fatigue, impatience, confusion and being inadequate were also presented:

House cleaning I cannot do in my own home, I cannot go to work and you become dissatisfied with yourself. Imagine everything you do-you use your hands and your arms and then imagine an adult with no arms and no hands-you feel powerless [...]. [The pain] is not only physical pain, it also affects me psychologically. You have your daily activities, you want to complete your work and when you have pain, you cannot get your work done, then you become dissatisfied with yourself and that affects your mind. Some days when I get up, I can hardly put on my clothes and some days I am so sad, so sad, I just sit down and cry because of the pain and because I cannot even get dressed. Sometimes you lose hope. (Pt 5) 


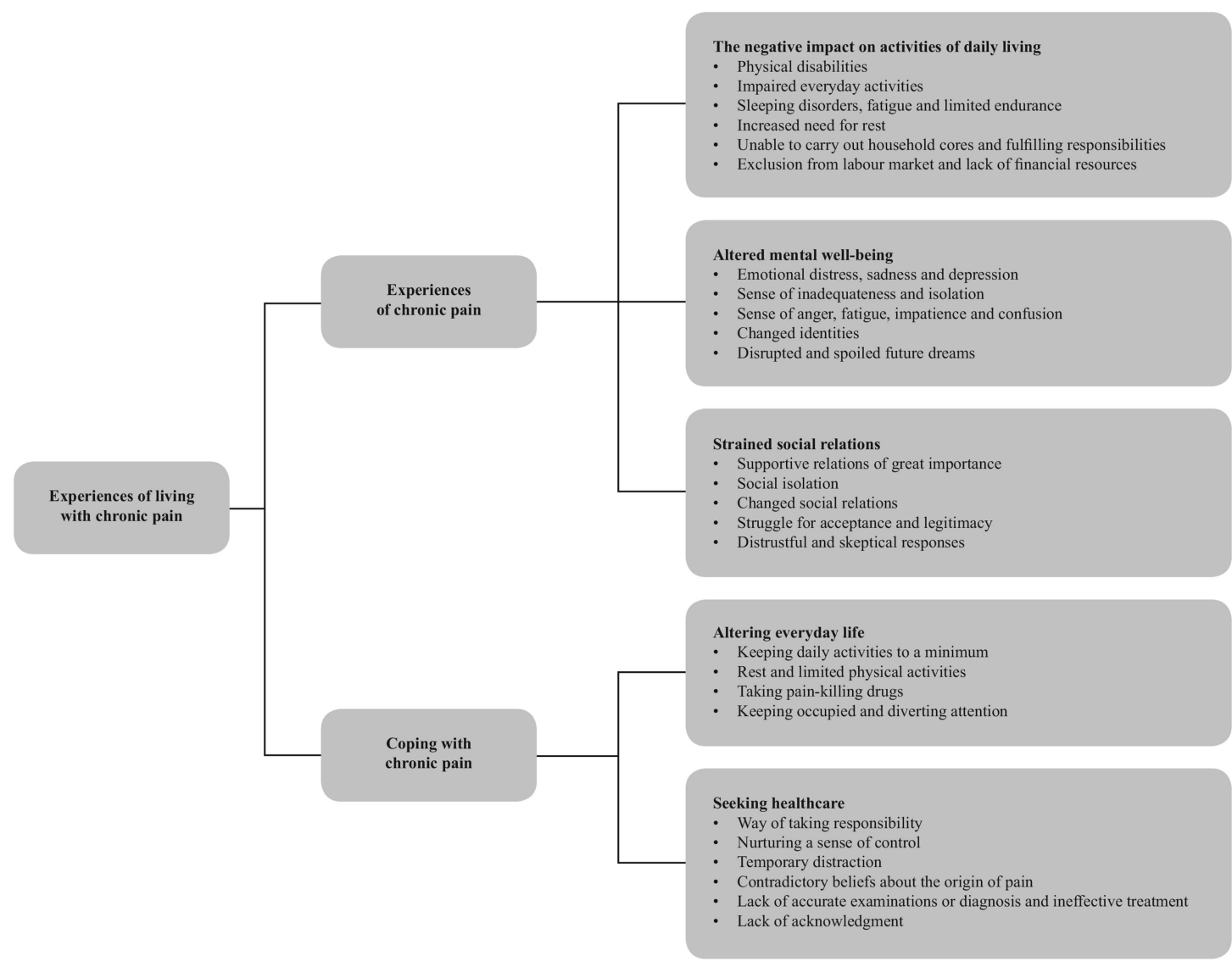

Figure 1 Variables influencing the experiences of chronic pain.

A temporal dimension appeared, as these emotional outcomes contrasted with women's perception of their former selves. Most women described themselves as once being strong and independent in various ways-in relation to children, husband, friends and work. They perceived themselves as having been physically and emotionally strong, healthy, having positive emotional attitudes, being resourceful and being conscientious workers, living up to responsibilities and duties. They described how the experience of pain had altered their perception of themselves, and a number of women found it difficult to reconcile themselves with their changed identities:

Maybe I am done living [...] I have never been like this before. [...] I was a strong woman, I was active, I was happy and I did many things myself. (Pt 13)

The women found pain and ailing to be a natural consequence of ageing. However, they experienced pain at a young age and the unexpected life situation was, for many of them, difficult to reconcile with. A woman explained it as being a young woman trapped in an old body, with her future taken away. Additionally, some women stressed how the pain disrupted and spoiled future dreams:
Right now, I do not have so many thoughts about the future, because I am afraid every day, I am worried about how things are going to be in the future [...]. I do not have so many dreams, I do not have so many goals. I would like to set some goals, but it will not let me, my situation, $[\ldots]$, so right now it is just about every day, in instalments. (Pt 6)

Interplay between several individual, social and structural determinants emerged, constituting a complex interaction that interfered with the experience of living with pain. One of the women described:

Firstly, I cannot work because of my pain, it affects my financial circumstances, and it affects me socially. It is like a line, you need to have all in succession, when you have a good economic situation, then you will also have it well socially. When you are healthy, then you are socially well too; it is a circle-when you are losing a ring, then you are losing it all. In my situation, many rings are missing, both money- and health-wise. Then you just feel empty inside. (Pt 12)

\section{Strained social relations}

All the women mentioned social relations as essential in relation to their health, but experienced the pain as interfering with the abilities to create and maintain social relations. Loss of social relations and being in social isolation emerged as the pain and the physical 
disability restricted mobility, and rendered the women unable to maintain leisure-time activities, invite friends and family to dinner or to engage in other social activities. Two women described how their inability to work resulted in a loss of social relations and valued colleagues, which further interfered with the experiences of pain:

When you work, then you are at least active socially, in many ways, but now I'm just at home. If I should describe it in numbers, if I was once at ten socially, now I'm just at one. I'm doing nothing, almost nothing. Also, financially, there are many reasons for it [social isolation]. Now I only receive cash welfare benefit; you cannot call a friend and go to a cafe and have a cup of coffee [...]. There are many reasons for this, both the pain and financial, so it is not only because of the pain. (Pt 12)

For some of the women, social isolation was perceived to be self-imposed. The fear of inappropriate appearance due to the unpredictable and uncontrollable pain resulted in them staying at home and avoiding social gatherings.

Also, the remaining social relations were reported to undergo changes with time, and most women described how previous roles, as parent, caregiver, friend and wife, were restricted due to the pain. Role reversals were described as an occurrence within most families and were perceived to have profound consequences for the family, in particular the children. The women struggled with maintaining motherhood roles and responsibilities despite the experience of chronic pain. Some described themselves as inadequate and stressed how they were no longer able to meet the needs of their children. The extensive effect on the children caused great distress:

It affects me a lot. For example, I would like to do all kinds of different cooking [for my children], but I have to figure out whether I can manage it or not, [...] changing the bed linen is so difficult for me; even though I do not wish the children to change their linen themselves, even though I wish to do it, I simply cannot. There are so many things I do not want my children to do, I want to do it myself, but I just cannot because of the pain. (Pt 12)

Nevertheless, the children and husband were perceived as the most important sources of practical help for maintaining everyday life. By providing social company, showing attention and being supportive in both emotional and practical ways, social relations, particular family and friends, could offer improved wellbeing for some of the women. Providing practical help enabled the women to avoid performing tasks causing pain and exhaustion, and helped them gain a sense of control over the pain. Some women explained how social relations could distract attention away from the pain for short periods of time. However, negative influences in social relationships also occurred, including unsupportive attitudes and behaviours, which, in addition, challenged the experiences and appearance of pain. Obtaining social support was an ongoing process involving a negotiation of the existence of the pain, convincing others about their credibility and a struggle for acceptance and legitimacy:

Before I was healthy and served him [husband] in every possible way and had children, he knows [...] I went to work, I came home and washed clothes, cleaned, did the ironing, all kind of things. Now I am ill, I cannot do that, he knows that I'm sick. (Pt 10)

Some experienced being met with scepticism and distrust, and found it difficult to justify the pain and its limitations. A woman further described how, restricted by her pain, she became unable to carry out her former duties resulting in distrustful and sceptical responses from her mother-in-law. Similar narratives occurred among other interviewees. Mostly, the women experienced that their husbands were dissatisfied and one woman explained how that ultimately led to divorce:

My husband, he has not [accepted my pain] [...]. We were happy with each other when I was young and healthy; then I could do all the things at home, all sorts of things, cleaning, taking care of the children and work and so on. When I was not able to do it any more, he started saying many things, and therefore I divorced my husband. (Pt 12)

\section{Coping with chronic pain}

The women described using a variety of strategies to manage the pain, even though it often seemed uncontrollable. Strategies were used to manage the consequences of the pain, maintain their everyday life and to restore a level of health that would enable them to function and complete their social roles.

\section{Altering everyday life}

All the women reported having personal coping strategies for easing and controlling the pain, and altering everyday lives in order to deal with the pain was a common strategy. Keeping daily activities to a minimum, limiting physical activities, taking pain-killing drugs, resting, keeping warm, using technical aids and getting help from others, were the most common coping strategies used to ease the pain and to some extent maintain everyday life. They mentioned the use of pain-killing drugs as a more direct means with which to control the pain even though it only provided temporary or no relief. Keeping occupied and diverting attention from the pain offered some women temporary relief.

However, the longstanding pain controlled the women, forcing them to adjust their lives:

It [the pain] affects me in an absolutely terrible way. I always have to be careful [...], when I am doing something $[\ldots]$. The next day, I become completely ill, so that is why I have to consider before I start doing something 
-tomorrow, how do I endure it, that is why I am only doing half or just avoid doing something altogether (Pt. 12)

Despite several coping strategies and efforts to ease the suffering, the pain was a recurrent problem that continually interfered with everyday life and caused a sense of powerlessness.

\section{Seeking healthcare}

The women articulated how chronic pain became the focus of their lives as longstanding periods of discomfort, numerous medical appointments and examinations and the search for a successful treatment structured and filled their time. An active use of healthcare services appeared as a way of attempting to manage the situation, thus trying to assert agency in coping with the pain. Seeking healthcare in this manner appeared as a supplementary means of coping with the pain, as it gave rise to a sense of agency, offering a way to manage an otherwise uncontrollable situation. Attending treatment and physiotherapy were furthermore mentioned as a temporary distraction from pain.

However, the women had suffered from chronic pain for several years with no actual improvement in their condition, and only a few mentioned trust in how they had been examined or diagnosed. Although most of the women had braced themselves for future pain, they did not want to reconcile themselves to that and all of them continued to seek healthcare in the search for a cure and, thereby, to control their pain. Although the women in general seemed to have a positive attitude towards healthcare, some voiced negative experiences such as dissatisfaction and disagreement. Contradictory beliefs about the origin of pain were reported often to appear in encounters with the healthcare profession; the women considered their pain to be a physical problem, while the physician explained it as a psychological problem due to depression and physiological distress as illustrated:

The doctor does not understand what is wrong with me. They only understand that I have depression and because of the depression I have this pain. I tell them: "No, I have not got depression, it is because of the pain I am depressed-because I am always in pain. I cannot cook or anything in the home or be responsible for my children as before. (Pt 4$)$

Dissimilar perceptions of the origin of pain were associated with feelings such as frustration and disorientation, making it difficult to identify appropriate coping strategies.

The women also described unsatisfactory care episodes with lack of accurate examinations or diagnosis, ineffective treatment, not being listened to or taken seriously. Constantly being referred for different examinations, and meeting new doctors and repeating their stories were described by some women as an unending stressful and uncertain situation, in which the pain and lack of appropriate examination and treatment limited their possibilities for regaining a sense of control in their lives.

\section{DISCUSSION}

This study contributes to the literature by showing that the experiences of chronic pain influenced broad aspects of the lives of female immigrant patients and had an extensive impact on their overall health-related quality of life. The pain reduced their ability to maintain their usual daily activities and to work. In addition, it involved emotional distress, depression and altered personalities with great consequences for the women's social interactions, including change in and loss of social relations. Therefore, a variety of strategies were drawn on to cope with the pain, manage the consequences, and to enable the women to function and complete social roles to some extent.

The physical disabilities from pain led to extensive restrictions, including persistent suffering, fatigue and limited endurance, preventing the women from living as previously. Everyday life was kept to a minimum, as they were no longer able to carry out daily activities, responsibilities and duties, and excluded from the labour market. Consequently, their poor economic status affected potential improvement by restricting the possibilities for direct and indirect health promotion behaviour, including the ability to attend regular treatment, the acquisition of technical aids, exercising, having a balanced $\operatorname{diet}^{24}$ and participating in social relations. Financial resources became a mediating resource, in which a lack of money became an additional stressor in the experiences of living with pain.

The pain furthermore interfered with the mental wellbeing of the women. Similar to other chronic pain studies among ethnic majority populations, several women experienced mental problems, such as depression, that they related to long-term pain experiences. $^{5} \quad 9 \quad{ }^{25-27}$ The longstanding suffering, the restrictions and the dependency on others, caused distress and a sense of inadequacy. The experiences of living with chronic pain and the extensive consequences on all aspects of life interfered with the women's selfimages. The perception of no longer being independent or having positive emotional attitudes as before led to a breakdown of self-image, thus changing the personalities of the women. However, they pointed out that the pain was not caused by individual weakness or personality or used as an excuse to avoid work. Experiences of breakdown of former self-images and the struggle for selfesteem were also identified as important in another study among women with chronic pain. ${ }^{27}$ These women continuously made efforts to maintain a positive and strong self-image in an attempt to convince others about the credibility of their version of their illness. As with this study's findings, the women distanced themselves 
from other women with similar pain to themselves, which might be an implicit approach to reject stereotyped medical accounts, and to avoid medical discourses about unexplained pain or cultural marginalisation and the perceptions of being a lazy, weak and illness-fixated female patient. ${ }^{27}$

Within the literature, the concept of 'ethnic pain' assumes immigrants to have different pain perceptions and behaviour than natives. However, the present findings concur with previous studies indicating that the experiences of living with chronic pain are not unique for immigrants. The interplay between the underlying causes of chronic pain are complex psychological and social factors determining the experiences of pain including levels of anxiety, depression, social support and coping strategies. ${ }^{16}$ Affiliation to an ethnic group or being an immigrant may not necessarily be responsible for differences in the perception and experience of pain, as these variations are affected and sometimes better explained by lack of socioeconomic resources and a low level of education. ${ }^{15} 28$

Social relations emerged as an important factor in the experiences of living with chronic pain, affecting experiences in both positive and negative ways. The importance of supportive relations was clearly expressed by all the women in relation to managing everyday life and handling the pain, ${ }^{13}$ and also in alleviating some of its consequences. ${ }^{14} 2930$ However, the pain restricted the ability to maintain and establish social relations and also affected inclusion in the labour market. Therefore, immigrant women may constitute a particularly vulnerable group among chronic pain patients due to the migration process, which often entails changes and loss of social relations. ${ }^{14} 29$

Even though social relations were physically available, they did not necessarily entail practical or emotional support. The women's stories illustrated that acknowledgment of the pain was of great importance, but not always achieved. Possessing a sick role, including a set of rights, privileges and temporal exemption from fulfilling normal social obligations, is a process that requires social validation ${ }^{26}{ }^{31}$ whereby the reactions of others and the cultural context lived in play an important role in the experience of chronic pain. ${ }^{27} 32$ Sceptics and unsupportive reactions challenged the possibilities of obtaining support and became additional stressors in the experiences of living with chronic pain. Additionally, Werner $e t a l^{27}$ found women struggling to be taken seriously, and struggling to be believed and understood in medical encounters and in social relations, when experiencing chronic but invisible pain.

However, the consequences of the chronic pain did not only exert an impact on the women; they also affected social relations, particularly the family, which underwent changes, with a role reversal occurring within most of them. This occurrence corresponds with previous studies of patients with chronic pain and their roles within their families in other countries, settings and populations. ${ }^{6}{ }^{13}$ Furthermore, Zander et $a l^{13}$ explained that the combination of forced resettlement and unpredictable pain results in a sense of loss of control and a dependency on society as well as on social relations, creating feelings of not being free. Moreover, our study also identified the distress of suddenly being dependent on and a burden to others, especially children. The women did not wish to encumber their children, even though most of them experienced doing so. In that way, pain led to a vicious circle, including different negative emotional feelings that might have resulted in a reduced pain threshold. ${ }^{89}$

As the present study illustrates, pain had become the focus of the women's lives and they had developed a variety of coping strategies. These were used to manage the consequences of the pain, maintain their everyday life and to restore a level of health that would enable them to function and complete their social roles. Altering daily lives by keeping daily activities to a minimum and taking pain-killing drugs offered a temporary relief, and were the most common ways of controlling the pain. Consistent with this research, other studies have found that diverting thoughts from the pain by keeping occupied could offer distraction and thereby ease the suffering. ${ }^{13}$ However, the women's situation was characterised by uncertainty, as they had struggled with pain for several years with no actual improvement. Without being able to find adequate strategies to cope with the pain, they had become dependent on healthcare professionals. Seeking healthcare entailed a number of potential options to overcome the pain and was perceived as an active means by which to control and cope with the pain, and a way of taking responsibility for their own health. Healthcare became an important source of hope, and expectation of forthcoming examinations enabled the women to envisage a better future, providing them with motivation and guidance for action. ${ }^{13}{ }^{33}$ However, numerous unsuccessful attempts at finding a cure or successful treatment consequently led to disappointments, mistrust and frustration, and an additional sense of lack of control. ${ }^{13}$ Knowing the origin of pain was perceived to be important, since it could lead to explanations and diagnosis, and help in choosing an appropriate treatment or action. ${ }^{26}{ }^{34}$ Therefore, dissimilar perceptions of the origin of pain caused great frustration and a feeling that the healthcare professional was discrediting the reality of the pain. In accordance, Newton et $a l^{25}$ found that the absence of physical pathology, adopting a psychological framework to understand the pain and its impact often occur, but such explanations given by the healthcare professionals are closely related to the experience of stigmatisation and discredit, which further threatens the identity of the individuals. Lack of appropriate examination and treatment also hindered the ability to regain a sense of control in their lives, and the ability to act towards or even envisage a future with no pain. 
Many of the findings in the present study are consistent with previous studies among the population of majorities, emphasising that the experiences and consequences due to chronic pain concern not only immigrant women, but chronic pain patients in general. ${ }^{5-79}$

\section{METHODOLOGICAL CONSIDERATIONS}

A limitation of the study was due to language. Offering interpreters during the interviews made it possible to include women who spoke little or no Danish, and four of the interviews were carried out with an interpreter. Conducting interviews with interpreters may affect the depth as well as the interpretation of the responses, either supporting or limiting the communication. Also, the use of online video interpretation may create a different interview context than 1:1 interviews, particularly due to the influence on the ability to create good interpersonal relationships shaped by trust and confidence. However, the interpreters were all trained in interpretation techniques and ethics, and some of the patients were familiar with the interpreters, which may have contributed to higher degree of informality and mutual trust in the interview situation. Furthermore, by using professional interpreters from the same area as the participants, an effort was made to diminish communication barriers/ difficulties. Additionally, we sought to ensure appropriate understanding between patients and interviewer by incorporating follow-up questions and rephrasing words during interviews, and by summarising our immediate understandings of patients' accounts during interviews.

Chronic pain is a term with a wide range of conditions, and the experience of living with it is shaped by health and living conditions in general. The subjective, dynamic nature of the pain experience causes a range of different situations facing the women who participated in the study. Despite this diversity, commonalities in experiences of the consequences of pain on quality of life and in coping strategies undertaken to manage pain emerged during analysis. We have sought to include both these shared experiences while acknowledging the particular situations and perceptions of individual women when relevant. The study population makes up a diversified group of patients with complex psychosocial and medical challenges, and might therefore constitute a particularly vulnerable population. Furthermore, this study consists of a relatively small sample size, including 13 in-depth interviews covering a diverse group of immigrants, and the heterogeneity must be taken into account when reviewing the findings in order to avoid broad generalisations.

Nevertheless, findings from the present study can be used to guide further research efforts. In order to understand the needs of populations with diverse ethnic and social backgrounds and to detect developments or changes in the experiences of pain, longitudinal qualitative studies among larger groups of immigrant women are needed. Future research among more homogeneous study populations, for example, patients sharing type and severity of disease, marriage status and country of birth or self-identified ethnicity, would be useful, as such studies might enable a deeper understanding of the influences of disease trajectory, social network and cultural factors on the experiences of living with chronic pain. Also, there is a need for studies exploring the experiences and coping strategies among migrant populations with less complex medical and psychosocial characteristics. Inclusion of perspectives of relatives and healthcare providers will further add to a more contextualised understanding of pain and coping. The similarities with populations of majorities points to the need for future comparative study, exploring similarities or differences in and between populations with diverse ethnic and social backgrounds. Having this insight would help to identify the needs of care, and to understand how to adjust care to meet the specific needs among immigrant women living with chronic pain, thereby improving healthcare.

\section{IMPLICATIONS FOR PRACTICE}

The results from this in-depth qualitative study add to the existing, mostly quantitative, literature by emphasising the extensive and adverse effect of chronic pain on all aspects of the women's lives. It further elucidates how their experiences of living with chronic pain were influenced by a range of individual, social and environmental factors, implying that healthcare professionals should take a holistic approach when supporting chronic pain patients.

To reduce the physical disabilities and the extensive consequences connected to social relations, physical and physiological health, early detection and examination are warranted. The women particularly grieved for their profoundly altered parenting role and the children appeared to bear a heavy responsibility. Enabling the women to manage and facilitate the well-being of the family despite the pain might, to some extent, alleviate the social and physiological consequences of pain. Consequently, healthcare professionals should take the family context into account, not only focusing on the individual, but facilitating a family-centred approach, also supporting children and other close family members. Finally, the restricted possibilities for regaining a sense of control over the pain and over their situation point to the importance of clinical encounters to entail clarification related to prognosis and treatments, and what to expect for future pain, as well as to avoid misunderstandings and stigmatisation.

Acknowledgements The authors would like to thank the participants for sharing their stories, and the staff members at SIM, and at the physio and occupational unit, who helped with the recruitment. Furthermore, we would like to thank Lisa Duus for her contribution to the study.

Contributors CM and MN conceived the study and all the authors developed the design. CM collected the data. The paper was drafted by CM, and revised and edited by all the authors. CM and MN are the guarantors.

Competing interests None declared. 
Funding Publication fees were provided by Section of Immigrant Medicine, Department of Infectious Diseases, Copenhagen University Hospital, Hvidovre, Denmark.

Ethics approval The study was approved by the Danish Data Protection Agency, I-Suite-nr 03233 and ID-nr AHH-2014-030.

Provenance and peer review Not commissioned; externally peer reviewed.

Data sharing statement No additional data are available.

Open Access This is an Open Access article distributed in accordance with the Creative Commons Attribution Non Commercial (CC BY-NC 4.0) license, which permits others to distribute, remix, adapt, build upon this work noncommercially, and license their derivative works on different terms, provided the original work is properly cited and the use is non-commercial. See: http:// creativecommons.org/licenses/by-nc/4.0/

\section{REFERENCES}

1. Merskey $\mathrm{H}$, Bond MR, Bonica JJ, et al. Classification of chronic pain: descriptions of chronic pain syndromes and definitions of pain terms. Http:/Www.lasp-Pain.Org/Files/Content/Contentfolders/Publications2/ Freebooks/Classification-Of-Chronic-Pain.Pdf (accessed 5 Nov 2014).

2. Harker J, Reid KJ, Bekkering GE, et al. Epidemiology of chronic pain in Denmark and Sweden. Pain Res Treat 2012;2012:1-30.

3. Kurita GP, Sjøgren $\mathrm{P}$, Juel K, et al. The burden of chronic pain: a cross-sectional survey focussing on diseases, immigration, and opioid use. Pain 2012;153:2332-8.

4. Sjøgren $\mathrm{P}$, Ekholm O, Peuckmann V, et al. Epidemiology of chronic pain in Denmark: an update. Eur J Pain 2009;13:287-92.

5. Breivik H, Collett B, Ventafridda V, et al. Survey of chronic pain in Europe: prevalence, impact on daily life, and treatment. Eur J Pain 2006;10:287-333

6. West $\mathrm{C}$, Usher $\mathrm{K}$, Foster $\mathrm{K}$, et al. Chronic pain and the family: the experience of the partners of people living with chronic pain. J Clin Nurs 2012;21:3352-60.

7. O'brien T, Breivik $\mathrm{H}$. The impact of chronic pain-European patients' perspective over 12 months. Scand J Pain 2011;3:23-9.

8. Mullersdorf M, Zander V, Eriksson $\mathrm{H}$. The magnitude of reciprocity in chronic pain management: experiences of dispersed ethnic populations of Muslim women. Scand J Caring Sci 2011;25:637-45

9. Jensen NH. Den Kroniske Smertepatient. In: Jensen TS, Dahl JB Arendt-Nielsen L, eds. Smerter-Baggrund, Evidens, Behandling. 3rd edn. København: FADL's Forlag, 2013:359-72.

10. Bergman S. Psychosocial aspects of chronic widespread pain and fibromyalgia. Disabil Rehabil 2005;27:675-83.

11. Sleptsova M, WöSsmer B, Grossman $P$, et al. Culturally sensitive group therapy for Turkish patients suffering from chronic pain: a randomised controlled intervention trial. Swiss Med Wkly 2013;143:w13875.

12. Taloyan M, Löfvander M. Depression and gender differences among younger immigrant patients on sick leave due to chronic back pain a primary care study. Prim Health Care Res Dev 2014;15:5-14.

13. Zander V, MüLlersdorf $M$, Christensson $\mathrm{K}$, et al. Struggling for sense of control: everyday life with chronic pain for women of the Iraqi diaspora in Sweden. Scand J Public Health 2013;41:799-807.
14. Meadows LM, Thurston WE, Melton C. Immigrant women's health. Soc Sci Med 2001;52:1451-8.

15. Bhopal RS. Migration, ethnicity, race, and health in multicultural societies. Oxford University Press, 2007.

16. Jones LE, O'shaughnessy DFP. The pain and movement reasoning model: introduction to a simple tool for integrated pain assessment. Man Ther 2014;19:270-6.

17. Cano A, Mayo A, Ventimiglia M. Coping, pain severity, interference, and disability: the potential mediating and moderating roles of race and education. J Pain 2006;7:459-68.

18. Löfvander MB, Furhoff AK. Pain behaviour in young immigrants having chronic pain: an exploratory study in primary care. Eur J Pain 2002;6:123-32

19. Norredam M. Migrants' access to healthcare. Dan Med J 2011;58: B4339.

20. Boateng L, Nicolaou M, Dijkshoorn H, et al. An exploration of the enablers and barriers in access to the Dutch healthcare system among Ghanaians in Amsterdam. BMC Health Serv Res 2012;12:75.

21. Jensen NK, Nielsen SS, Krasnik A. Expert opinion on "best practices" in the delivery of health care services to immigrants in Denmark. Dan Med J 2010;57:A4170.

22. Malterud K. Systematic text condensation: a strategy for qualitative analysis. Scand J Public Health 2012;40:795-805.

23. Klintefelt T, Laursen L, Larsen D, et al. Indvandrere I Danmark 2013 Danmarks Statistik, 2013.

24. Diderichsen F, Andersen I, Manuel C. Ulighed I Sundhed-Årsager Og Indsatser. København: Sundhedsstyrelsen, 2011.

25. Newton BJ, Southall JL, Raphael JH, et al. A narrative review of the impact of disbelief in chronic pain. Pain Manag Nurs 2013;14:161-71.

26. Glenton C. Chronic back pain sufferers-striving for the sick role. Soc Sci Med 2003;57:2243-52.

27. Werner A, Isaksen LW, Malterud K. 'I am not the kind of woman who complains of everything': illness stories on self and shame in women with chronic pain. Soc Sci Med 2004;59:1035-45.

28. Ernst $\mathrm{G}$. The myth of the 'Mediterranean syndrome': do immigrants feel different pain? Ethn Health 2000;5:121-6.

29. Kristiansen M, Tjørnhøj-Thomsen T, Krasnik A. "Sometimes you just have to walk alone"-meanings of emotional support among Danish-born and migrant cancer patients. J Psychosoc Oncol 2010;28:699-717.

30. Taylor B, Carswell K, Williams AC. The interaction of persistent pain and post-traumatic re-experiencing: a qualitative study in torture survivors. J Pain Symptom Manage 2013;46:546-55.

31. Nettleton S. Chronic illness and disabilities the sociology of health and illness. 2nd edn. Polity, 2006:71-103.

32. Charmaz K. Loss of self: a fundamental form of suffering in the chronically ill. Sociol Health IIIn 1983;5:168-95.

33. Kristiansen M, Irshad T, Worth A, et al. The practice of hope: a longitudinal, multi-perspective qualitative study among South Asian Sikhs and Muslims with life-limiting illness in Scotland. Ethn Health 2013;19:1-19.

34. Jackson J. Chronic pain and the tension between the body as subject and object. In: Csordas TJ, ed. Embodiment and experience: the existential ground of culture and self. Cambridge University Press, 1994:201-227. 